\title{
The Effect of Socio-economic status on the Oral Hygiene of Elementary School Children in the City of Dammam, Saudi Arabia
}

\author{
Authors \\ Albraithen Abdulrahman, Alsulaiman Ahmed, Alrumaih Hamad, Alfaleh Saleh, \\ Alsunaidi Abdullah
}

\begin{abstract}
The purpose of this paper was to determine the status of the oral health of children compared to the socioeconomic status (SES) of the parents in the city of Dammam, Saudi Arabia. Three schools were targeted based on the SES levels; two private schools and one governmental school. The sample size was 40 boys from each school all of them $5^{\text {th }}$ grade students. The dependent variable was the oral hygiene status of the children and the independent variables were the school type (governmental or private), parents' education and socioeconomic status. Community SES was significantly related to oral hygiene status. Overall, oral health was significantly worse for low SES communities. There is a direct relationship between SES and oral hygiene status of children in elementary schools in the community of Dammam, Saudi Arabia. In which high caries prevalence was seen with children attending public school.

Keywords- Oral Hygiene, Dental, Socio-economic.
\end{abstract}

\section{INTRODUCTION}

Good oral health is a goal that is only achieved by having all the "correct" items to fulfill that goal. These items that are highly related to having a good oral health are proper oral hygiene practice, welleducated people and neighborhood of residency.

Moreover, Socio-economic status (SES) is a description of a person's societal status using factors or measurements such as income level, relationship to the national poverty line, educational achievement and neighborhood of residency. ${ }^{1}$

Poor SES has been a known risk factor to poor oral health. Numerous studies were conducted, In which Gillcrist, Brumley and Blackford concluded that community SES was significantly related to caries experience in the primary teeth, the proportion of untreated caries in the primary and permanent teeth, dental treatment needs, dental sealants and incisor trauma. Overall, dental health was significantly worse for low-SES communities than for mediumand high-SES communities. ${ }^{2}$ Also, Reisine and Poster said that underlying mechanisms may not be well understood, low SES may serve clinicians as a marker for increased risk of caries. ${ }^{3}$

In addition, Poverty in at least one stage of the lifespan has a harmful effect on dental caries, oral behaviors and dental services use. Belonging to upwardly mobile families between childhood and adolescence only contributed to improved dental care. ${ }^{4}$ Moreover, Rosa said that the higher SES receives more dental care than the low SES. 
Since this relationship is known to be important, and due to lack of studies in our region, a necessity was needed to further examine the relationship between oral hygiene and SES.

Therefore, The aim of the study was to determine the status of the oral health of children compared to the SES of the parents in the city of Dammam, Saudi Arabia.

\section{Material and Methodology}

The type of school that the child attends dictates what SES he belongs to. In Saudi Arabia education in general is free of charge, however, the need for private school exists, where some parents have references on the type of education they want their children to attend. Private schools are good indication on the SES to the child belongs to. In our study we targeted three schools based on the SES levels; two private schools [Noor alislam primary school (NIS), Aljamah primary school(AJS)] and one governmental school [Abdulla Bin Abbas governmental school(AAS)] in Dammam, Eastern province of Saudi Arabia. The sample size was 40 boys from each school all of them $5^{\text {th }}$ grade students (this sample size was chosen due to limited time and resources in the public health course of college of dentistry, Dammam University, in which this study is a part of the requirements for it).

The study comprised of an educational presentation using a laptop and projector. The lecture included general information about dental caries and periodontal disease and how to maintain good oral hygiene. Following each lecture the students were divided into small groups, each group assigned to one of the to demonstrate the proper way of brushing and flossing using jaw models and toothbrush.

A pamphlet, demonstrating brushing and flossing technique was printed and distributed in all three schools. At the end of the lecture each child received a pamphlet and clinical examination .The examination was conducted using a penlight and tongue blade. Oral hygiene was examined using oral hygiene index simplified (OHI-s), which consists of derbies index (DI) and calculus index (CI) in which two students examined participants with a help of other two students. Also, the caries prevalence was measured using the DMFt index for permanent teeth and dft index for primary teeth.

Prior to the visit, and in order to compare the socioeconomic status of parents to the oral hygiene status of the children, a questionnaire was prepared and distributed to the children two days before the lecture and collected during the examination of each child to register the clinical findings on the same questionnaire page.

The data was collected using the clinical findings according to indices mentioned above and the questionnaire that has been distributed previously.

The dependent variable was the oral hygiene status of the children and the independent variables are the school type (governmental or private), parents' and socioeconomic status.

The father and mother educational level was divided into four groups (below high school, high school, bachelor degree and highly educated). Also, the monthly income of the parents was divided into three groups, the first group with a monthly income of $<5,000 \mathrm{SR}$ (low), the second group with an average income of 5,000-15,000 SR (average), and the third group with a highly income of $>15.000 \mathrm{SR}$ (high). In addition, the DMFt was categorized into three groups, the first category was with a good score of (0-3), the second category was with an average score of (4-6) and the third category was with a low score of (7-9).

The OHI-s was categorized into three groups, the first category was with a good score of (0-1), the second category was with an average score of $(>1$ $<2.33)$ and the third category was with a low score of (2.33-3.50). (table-1)

Table-1: Dependent variables categorization

\begin{tabular}{|l|l|}
\hline Variables & Categorization \\
\hline OHI-s: & Good score \\
$0-1$ & Average score \\
$1-<2.33$ & Low score \\
$2.33-3.5$ & \\
\hline DMFt: & Good score \\
$0-3$ & Average score \\
$4-6$ & Low score \\
$7-9$ & \\
\hline
\end{tabular}

The SPSS statistics 18.0 was used for statistical analysis of the sum sample. 


\section{Results}

The results of the study regarding the different decisive variables were of $90.2 \%$ Saudis, the father educational level showed a mode of $42.9 \%$ having a bachelor degree, in which NIS had $55.8 \%$ and AJS had $43.8 \%$ bachelor degree holders while AAS had $61.9 \%$ high school certificate holders. Also, the mother educational level showed a mode of $47.4 \%$ having a bachelor degree, in which NIS had $60.5 \%$ and AJS had $72.9 \%$ bachelor degree holders while AAS had $73.8 \%$ high school certificate holders.

Graph-1: Clinical indices based on type of school.

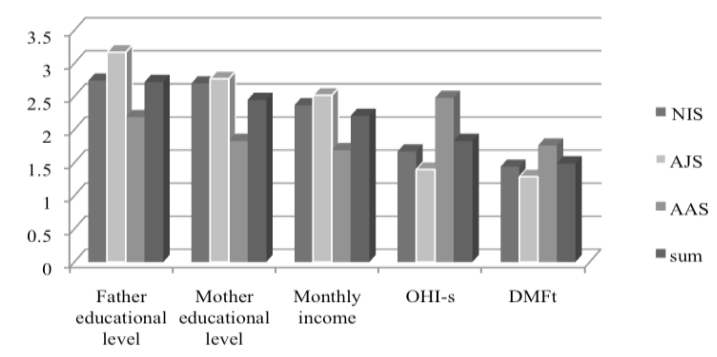

The monthly income showed a mode of an average income of $47.7 \%$ in which NIS showed $53.5 \%$ average income, AJS showed highly income of $56.3 \%$ while AAS showed $50 \%$ average income.

DMFt showed a mode of $57.1 \%$ of a good score in which NIS showed a good score of $62.8 \%$, AJS showed $70.8 \%$ good score and AAS showed $52.4 \%$ average score.

OHI-s showed a mode of $40.6 \%$ of an average score in which NIS showed an average score of (48.8\%), AJS showed $64.6 \%$ good score and AAS showed $52.4 \%$ low score. The summaries of the results are described in (table-2).

Table-2: Frequencies and modal distributions

\begin{tabular}{|c|c|c|c|c|}
\hline Variables & Frequenc & & & \\
\hline School code & $\begin{array}{l}\text { NIS* } \\
\text { N (\%) } \\
\end{array}$ & $\begin{array}{l}\text { Ajs* } \\
\mathrm{N}(\%) \\
\end{array}$ & $\begin{array}{l}\text { AAS* }^{*} \\
\mathrm{~N}(\%)\end{array}$ & $\begin{array}{l}\text { Total } \\
\mathrm{N}(\%)\end{array}$ \\
\hline $\begin{array}{ll}\begin{array}{l}\text { Number } \\
\text { participants }\end{array} & \text { of } \\
\end{array}$ & 43 & 48 & 42 & 133 \\
\hline $\begin{array}{l}\text { Nationality } \\
\text { Saudi } \\
\text { Non-Saudi }\end{array}$ & $\begin{array}{l}43(100) \\
0(0)\end{array}$ & $\begin{array}{l}39(\mathbf{8 1 . 3}) \\
9 \quad(18.7) \\
\end{array}$ & $\begin{array}{l}38 \text { (90.5) } \\
4(9.5)\end{array}$ & $\begin{array}{l}120(\mathbf{9 0 . 2}) \\
13 \quad(9.8)\end{array}$ \\
\hline $\begin{array}{l}\text { Father edu. level } \\
\text { < high school } \\
\text { High school } \\
\text { Bachelor degree } \\
\text { Highly educated }\end{array}$ & $\begin{array}{ll}2 & (4.7) \\
12 & (27.9) \\
\mathbf{2 4} & (\mathbf{5 5 . 8}) \\
5 & (11.6) \\
\end{array}$ & $\begin{array}{l}1 \quad(2.1) \\
8(16.7) \\
\mathbf{2 1}(\mathbf{4 3 . 8}) \\
18(37.5) \\
\end{array}$ & $\begin{array}{ll}4 & (9.5) \\
\mathbf{2 6} & (\mathbf{6 1 . 9}) \\
12 & (28.6) \\
0 \quad(0) \\
\end{array}$ & $\begin{array}{ll}7 & (5.3) \\
49 & (34.6) \\
\mathbf{5 7} & \mathbf{( 4 2 . 9 )} \\
23 & (17.3) \\
\end{array}$ \\
\hline $\begin{array}{l}\text { Mother edu. level } \\
\text { < high school } \\
\text { High school }\end{array}$ & $2(4.7)$ & $2(4.2)$ & 9 (21.4) & $13 \quad(9.89)$ \\
\hline
\end{tabular}

\begin{tabular}{|c|c|c|c|c|c|}
\hline $\begin{array}{l}\text { Bachelor degree } \\
\text { Highly educated }\end{array}$ & $\begin{array}{l}12(27.9) \\
26(60.5) \\
3(7)\end{array}$ & $\begin{array}{ll}9 & (18.8) \\
\mathbf{3 5} & (\mathbf{7 2 . 9}) \\
2 & (4.2)\end{array}$ & $\begin{array}{ll}31 & (\mathbf{7 3 . 8}) \\
2 & (4.8) \\
0 & (0)\end{array}$ & $\begin{array}{l}52 \\
63 \\
5\end{array}$ & $\begin{array}{l}(39.1) \\
\mathbf{( 4 7 . 4 )} \\
(3.8)\end{array}$ \\
\hline $\begin{array}{l}\text { Monthly income } \\
\text { Low } \\
\text { Average } \\
\text { High }\end{array}$ & $\begin{array}{l}2(4.7) \\
\mathbf{2 3}(\mathbf{5 3 . 5}) \\
18(41.9)\end{array}$ & $\begin{array}{l}2(4.2) \\
19(39.6) \\
\mathbf{2 7}(\mathbf{5 6 . 3})\end{array}$ & $\begin{array}{l}17(40.5) \\
\mathbf{2 1}(\mathbf{5 0 )} \\
4 \quad(9.5) \\
\end{array}$ & $\begin{array}{l}21 \\
63 \\
49 \\
\end{array}$ & $\begin{array}{l}(15.8) \\
\mathbf{( 4 7 . 4 )} \\
(36.8) \\
\end{array}$ \\
\hline $\begin{array}{l}\text { DMFt } \\
\text { Good } \\
\text { Average } \\
\text { Low } \\
\end{array}$ & $\begin{array}{l}27(\mathbf{6 2 . 8}) \\
13(30.2) \\
3(7) \\
\end{array}$ & $\begin{array}{l}34(\mathbf{7 0 . 8}) \\
14(29.2) \\
0 \quad(0)\end{array}$ & $\begin{array}{lr}15 & (35.7) \\
22 & (52.4) \\
5 & (11.9) \\
\end{array}$ & $\begin{array}{l}76 \\
49 \\
8 \\
\end{array}$ & $\begin{array}{l}\mathbf{( 5 7 . 1 )} \\
(36.8) \\
(6)\end{array}$ \\
\hline $\begin{array}{l}\text { OHI-s } \\
\text { Good } \\
\text { Average } \\
\text { Low } \\
\end{array}$ & $\begin{array}{l}18(41.9) \\
21(\mathbf{4 8 . 8}) \\
4(9.3)\end{array}$ & $\begin{array}{l}31(\mathbf{6 4 . 6 )} \\
15(31.3) \\
2(4.2)\end{array}$ & $\begin{array}{ll}2 & (4.8) \\
18 & (42.9) \\
\mathbf{2 2} & (\mathbf{5 2 . 4})\end{array}$ & $\begin{array}{l}51 \\
54 \\
28 \\
\end{array}$ & $\begin{array}{l}(38.3) \\
(40.6) \\
(21.1) \\
\end{array}$ \\
\hline \multicolumn{6}{|c|}{$\begin{array}{l}\text { Bold font: Modal distribution. } \\
\text { *NIS: Noor Alislam private school. } \\
\text { AJS: Aljamah private school } \\
\text { AAS: Abdullah bin Abbas school. } \\
\text { three variables which are the father education, Mother education and the } \\
\text { monthly income. }\end{array}$} \\
\hline
\end{tabular}

\section{Discussion}

The results showed that $41 \%$ of the whole sample had an average score regarding OHI-s with $43 \%$ of them having parents with high school degree. Also, the results showed that $57 \%$ of the whole sample had a good DMFt score with $83 \%$ of them having parents with highly educated degrees.

Graph-2: Mean Oral Hygiene Index of the school children (OHI-s) based on type of school

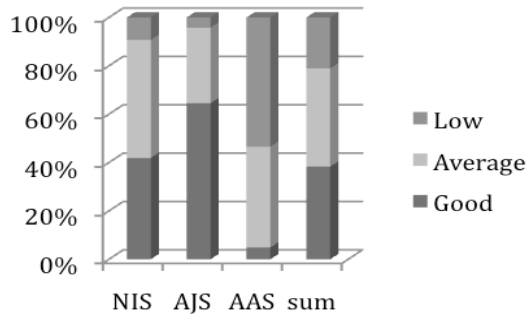

In order to reach a comparison between the oral hygiene of the children and the SES, We compared the OHI-s and DMFt with three variables which are the father education, Mother Education and the monthly income.

Regarding the relationship between the OHI-s and the mother's educational level, $41 \%$ of the participants had an average score with $60 \%$ highly educated mothers and $38 \%$ of a good score participants having 57\% mothers holding a bachelor degree. Also, $21 \%$ of the participants had a low score with $43 \%$ high school educated mothers and $39 \%$ of them with mothers holding a below high school degree. 
In other hand, the relationship between the DMFt and mother's education, two thirds of the mothers with a bachelor degree and $60 \%$ of highly educated mothers had a good DMFt score for their children's, which consists of $57 \%$ of the total sample.

Regarding the relationship between the monthly income and OHI-s, $62 \%$ of low-income parents had a low OHI-S score while $55.1 \%$ of highly income parents had a good OHI-s score.

Moreover, the relationship between the monthly income and DMFt, $71 \%$ with highly income had a good score for their children and none of the participants with a high income had a low score.

In addition, the Governmental school had lower score regarding the OHI-s and DMFt in which 22 out of 42 had a low OHI-S and Also an average DMFt. However, the private schools had a better OHI-S and DMFt scores, in which two thirds of the participants had a good score regarding DMFt and more than half of them having a good score in the OHI-S. This was a reflection of the parents' educational level and income in the private schools compared to the governmental school.

Graph-3: Mean Decayed, Missing, Filled teeth (DMFt) of the school children based on type of school

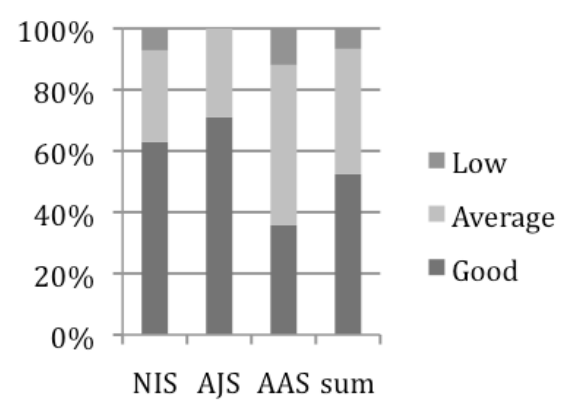

Also the results showed that AJS had a higher oral hygiene scores regarding both DMFt and OHI-s due to the fact that AJS had a higher parental income and higher parental educational level.

\section{Conclusion and Recommendation}

There is a direct relationship between SES and oral hygiene status of children in elementary schools in the community of Dammam, Saudi Arabia. In which high caries prevalence was seen with children attending public school. Further improvements in oral health will necessitate that community based preventive programs and access to quality dental care be made available to children who are identified as being at highest risk of experiencing oral diseases.

\section{References}

1. Centers for Disease Control and Prevention, Department of Health and Human Services, Atlanta, GA, USA.

2. James A. Gillcrist; David E. Brumley; Jennifer U. Blackford, Community socioeconomic status and children's dental health, JADA 2001;132;216-222.

3. Susan Reisine; Walter poster. Socioeconomic Status and Selected Behavioral Determinants as Risk Factors for Dental Caries, Journal of Dental Education 2001;1009-1016.

4. Marco Aure'lio Peres, Karen Glazer Peres, Alu1'sio Jardim Dornellas de Barros, Cesar Gomes Victora. The relation between family socioeconomic trajectories from childhood to adolescence and dental caries and associated oral behaviors, J Epidemiol Community Health 2007;61;141-145.

5. Manuel De La Rosa, Dental caries and socioeconomic status in Mexican children, $\mathrm{J}$ Dent Res 57(3): 453-457, March 1978. 